\title{
Interactive comment on "OSL rock surface exposure dating as a novel approach for reconstructing transport histories of coastal boulders over decadal to centennial timescales" by Dominik Brill et al.
}

\section{Pedro Costa (Referee)}

ppcosta@dct.uc.pt

Received and published: 11 August 2020

Dear authors, many thanks for the opportunity to review your manuscript on OSL rock surface exposure dating as a novel approach for reconstructing transport histories of coastal boulders over decennial to centennial timescales.

Your manuscript is very well prepared. It is nicely written and fits perfectly within the scope of the journal. The figures serve their purposes very well. In fact they illustrate with high-quality the reasoning forwarded and facilitates the reader's job because they 
are very informative. Nevertheless, their number seems a bit excessive and a couple of them couple be merged (e.g.A14-A15-A16).

ESurfD

The text flows well and, with the exception of very few misspelling words, it is impeccable to read. References seen to be updated and formulas used are properly formatted.

Regarding science, this manuscript focus on one key issue on storm and marine deposits, namely in boulder deposits. It is a known problem to accurately date the transport of these boulders in coastal settings and it is a theme that have constrained the accurate establishment of return periods and hazard assessments in many locations worldwide. The authors used a well-controlled setting within a short-time window of observation which allowed comparison with aerial/satellite imagery. Thus, narrowing time-interval of transport being studied. The concept and the example selected is interesting and very sound. However, several question still remain to be answered. I will raise a few below but first would like to stress that I feel this manuscript clearly addresses a relevant topic and, with the results presented, moves science forward.

The "new" OSL methodology presented is robust and should/needs to be further tested in other locations. A shame we do not have this methodology compared with other dates from other previously studied locations. The fact that is from specific locations clearly puts forward its potential but still leaves some doubts regarding its reliability. It would be interesting to have further direct age comparisons.

One aspect that concerns me is the obvious dependence on mineralogy. Limestone coastal areas will still be a challenge and one that needs to be addressed. Nevertheless, this manuscript clearly points very interesting future research directions.

The mineralogy-dependence is an obvious constrain to this methodology. This is also evident when we have weathering or erosion. There are micro-erosion meters and they should have been used. I am aware erosion meters have slow rates and require a larger time-window of observation, nevertheless the modeled erosion rates represent for me a huge degree of uncertainty that might have been avoided with empirical data.

Interactive comment

Printer-friendly version

Discussion paper 
Furthermore, these rates are highly controlled by lithology, mineralogy and texture. So, this section of the manuscript is valuable but would benefit from a larger discussion on its shortcomings. Furthermore, this is a key issue in the new OSL methodology: before dating the surface, one must very accurately establish the erosion since deposition.

Regarding the study case, it has been widely established that in many coasts along the North Atlantic from Iceland (Etienne and Paris, 2010), Ireland (Cox et al., 2019) to Portugal (Oliveira et al., 2020) boulder deposits are essentially associated with storm events. There are occasional cases where tsunami origin has been discussed but many times with caution. In that sense, the authors should be less bold on lines 470475 in particular when comparing case studies with multiple dating methodologies with others with a single methodology or even with just a single measurement. So, the dominance of short-lived and frequent storms on the creation and shaping of boulder deposits is natural in particular in areas not so prone to tsunami events like the North Atlantic. This raises the issue of poor and difficult recognition of tsunami boulder deposits except when very specific dates are obtained (which is very difficult) or when size of boulders and its heights allows to disregard storm origin...but even then, there is the possibility of being palaeo-storm signatures of past higher sea-levels. So, to conclude the data provided from the study case reinforces the reasoning above and I recommend the authors to stress this aspects by adding a couple of sentences on this.

My comments are broadly generic. I enjoyed the manuscript and it certainly deserves to be published after minor changes. Once more, many thanks for the opportunity to review this manuscript. Regards Pedro JM Costa

Interactive comment on Earth Surf. Dynam. Discuss., https://doi.org/10.5194/esurf-2020-46, 2020.

\section{ESurfD}

Interactive comment
Printer-friendly version

Discussion paper 